\title{
Nefopam for the prevention of perioperative shivering: a meta-analysis of randomized controlled trials
}

\author{
Meng Lv ${ }^{1 \dagger}$, Xuetao Wang ${ }^{2 \dagger}$, Wendong Qu ${ }^{3 \dagger}$, Mengjie Liu ${ }^{1 \dagger}$ and Yuelan Wang ${ }^{1{ }^{*+}}$
}

\begin{abstract}
Background: Shivering is a frequent complication following surgery and anaesthesia. A large variety of studies have been reported that nefopam may be efficacious for the prevention and treatment of perioperative shivering. Regrettably, there is still no conclusion of the efficacy and safety of nefopam for the prevention of perioperative shivering. The aim of this analysis is to evaluate the efficacy of nefopam for the prevention of perioperative shivering in patients undergoing different types of anaesthesia compared with placebo group and other active interventions.
\end{abstract}

Methods: PubMed, EMBASE, Cochrane Central Register of Control Trials were systematically searched for potentially relevant trials. Trial quality and extracted data were evaluated by two authors independently. Dichotomous data on the absence of shivering was extracted and analysed by using relative risk (RR) with $95 \%$ confidence interval (Cl). Continuous outcome was abstracted and analysed by using weighted mean difference (WMD) with $95 \%$ confidence interval (CI). Outcome data was analysed by using random effect model or fixed effect model in accordance with heterogeneity.

Results: Compared with placebo, prophylactic administration of nefopam significantly reduced the risk of perioperative shivering not only in the patients under general anaesthesia but also neuraxial anaesthesia (RR 0.08; $95 \% \mathrm{Cl} 0.05-0.13$ ). As compared with clonidine, nefopam was more efficacious in the prevention of perioperative shivering (RR 0.34; $95 \% \mathrm{Cl}$ 0.17-0.70). Nefopam has no influence on the extubation time (WMD 0.92; $95 \% \mathrm{Cl}-0.15-1.99$ ).

Conclusion: Our analysis has demonstrated that nefopam is associated with the decrease of risk of perioperative shivering following anaesthesia without influencing the extubation time.

Keywords: Nefopam, Shivering, Meta-analysis

\section{Background}

Shivering is a distressing and frequent side effect during the intra-operative period [1], which might hinder monitoring [2]. Shivering never causes direct demise of patients and it is unlikely to become chronic. However, it is associated with the increase of oxygen consumption, which would endanger a patient with compromised cardiac function. The mechanism of perioperative shivering is not completely clear. Shivering may act as a response to hypothermia. Whereas, shivering happens even with

\footnotetext{
*Correspondence: wyldgf@163.com

${ }^{\dagger}$ Equal contributors

'Department of anesthesiology, Qianfo shan Hospital, Shandong University, Jinan, Shandong, China

Full list of author information is available at the end of the article
}

normothermia in the perioperative period, suggesting that other origins than heat loss and subsequent decrease in body temperature may lead to the development of shivering [3]. Moreover, keeping patients normothermia is not always available. Thus, it is essential to prevent shivering by using pharmacologic interventions in a special case for selected patients.

A large variety of regimens have been demonstrated to be efficacious in the prevention and treatment of postanesthetic shivering, such as $\alpha 2$-agonist $[4,5]$, tramadol $[1,6]$, meperidine $[7,8]$, serotonin-3 receptor antagonist [9]. There is still no "gold standard" intervention for the prevention of perioperative shivering. To our knowledge, 
nefopam may hold the best promise due to its efficacy [10-12] without any serious adverse effects [13].

Nefopam, a benzoxazocine substance, is structurally related to orphenadrine and dyphehydramine [14]. Nefopam is neither a non-steroidal anti-inflammatory drug nor an opiate [15]. Nefopam is not associated with respiratory inhibition [16]. The mechanisms of nefopam involved in the anti-shivering and thermoregulatory action are not completely demonstrated. Nefopam inhibits the synaptic reuptake of dopamine, norepinephrine, and serotonin in an amphetamine fashion [17]. Nefopam affected thermoregulatory response via $\alpha_{2}$ adrenoceptors [18].

The aim of this review is to investigate the effectiveness of nefopam for preventing perioperative shivering and the influence of nefopam on the extubation time. The secondary aim of this analysis is to compare the efficacy of nefopam with the other active interventions for the prevention of perioperative shivering.

\section{Methods}

We systematically screened the Medline (1966 - February 2015), EMBASE (1980 - February 2015), Cochrane Central Register of Controlled Trials (CENTRAL) (The Cochrane Library 2015, Issue 2) by using different search strategies. Potentially relevant randomised controlled trials (RCT) were searched by using search methods found in (Appendix 1 MEDLINE silver platter); (Appendix 2 EMBASE silver platter); (Appendix 3 CENTRAL). Grey literature and Conference proceedings were manually searched. Relevant investigators were contacted for supplemental data and special question. Additional articles were identified from reference lists of retrieved articles. No language restriction was applied in this study. The date of last search was February 18, 2015.

Randomised controlled trials of prophylactic administration of nefopam to prevent perioperative shivering were included in this analysis. Only standard randomised controlled trials were taken into account; quasirandomized controlled studies, cluster-trials and crossover trials were excluded. Active controlled trials without placebo group or inactive group were excluded. Studies with limited number of patients were excluded. Data from retrospective studies, nonsurgical settings studies or experimental studies in volunteers were not included. We only considered trials that investigated prophylactic use of nefopam for preventing perioperative shivering in adults undergoing surgery. Different doses of nefopam were tested in the included studies. We excluded the trials that were related to the treatment of shivering.

Each title and abstract of references was screened by two authors to exclude obvious irrelevant articles with disagreement resolved by consensus. If potentially relevant, the complete articles were retrieved. Two reviewers independently read the articles in complete form to determine the final inclusion. Consensus of inclusion of the studies was reached by discussion. Reviewers were not blinded to trial authors, institutions, journal of publication, and results of study.

The following inclusion criteria were used for potentially pertinent studies: random allocation, comparison of nefopam versus placebo, performed on surgical patients with no restraints on dose and timing of administration. The exclusion criteria were duplicate publications, nonhuman trials, without main outcome, studies in healthy volunteers and data from abstracts or letters.

Data were collected by two investigators from the selected studies, with disagreement resolved by consensus. We obtained the information on patients, anesthetic methods, interventions, outcomes, body temperature, different doses of nefopam and adverse effects.

For dichotomous outcome, data was extracted as the number of patients with outcome event and the number of patients in the treatment group and placebo group. A large variety of efficacy endpoints of shivering were reported in these studies. In order to reduce the interpretational bias, we only extracted efficacy data on complete absence of shivering. For continuous outcome, data was expressed as mean value and standard deviation (SD). Some of the included trials were multiple-arm studies. When we extracted the continuous data from these trials, it was necessary to combine multiple groups into a single one. The SD and mean values of the combined group were calculated according to the method of the Cochrane Handbook of Systematic Review of interventions [19] (Table 1).

The risk of bias of the included studies was assessed by using the Cochrane Collaboration's protocol [20]. The articles were reviewed to arrive a final score if there was a discrepancy.

Relative risk (RR) with pertinent $95 \%$ confidence intervals (CI) were calculated for binary outcomes. A statistical significance between nefopam group and control group was assumed if the $95 \%$ CI of the RR excluded 1 . In the presence of significant heterogeneity, we intended to use random-effect method. If there was not statistically significant heterogeneity, the fixed effect method was used. As an estimate of statistically significant difference between nefopam and untreated control group for continuous variable, we calculated weighted mean difference (WMD) with $95 \%$ CI. If the $95 \%$ CI of WMD did not include 0 , we considered that the difference between nefopam and control was significant. Heterogeneity and inconsistency were evaluated by $\mathrm{Q}$ and $\mathrm{I}^{2}$ test respectively. When the $\mathrm{P}$ value of $\mathrm{Q}$ test was greater than 0.10 and $\mathrm{I}^{2}$ was less than $50 \%$, we regarded it as homogeneity. The subgroup analysis was based on different anesthetic methods, general anaesthesia and neuraxial 
Table 1 Formula for combining groups of continuous data

\begin{tabular}{llll}
\hline & Group 1 & Group 2 & Combined group \\
\hline Sample size & $N_{1}$ & $N_{2}$ & $N_{1}+N_{2}$ \\
Mean & $M_{1}$ & $M_{2}$ & $\frac{N_{1} M_{1}+N_{2} M_{2}}{N_{1}+N_{2}}$ \\
Standard Deviation & $S_{1}$ & $S_{2}$ & $\sqrt{\frac{\left(N_{1}-1\right) S D_{1}{ }^{2}+\left(N_{2}-1\right) S D_{2}{ }^{2}+\frac{N_{1} N_{2}}{N_{1}+N_{2}}\left(M_{1}{ }^{2}+M_{2}{ }^{2}-2 M_{1} M_{2}\right)}{N_{1}+N_{2}-1}}$ \\
\hline
\end{tabular}

anaesthesia. Two sensitivity analyses were planned $a$ prior to explore the heterogeneity. First, calculation that used the fixed effects model was repeated by using the random effect model. Second, some trials were retracted from the journal due to ethical reasons. Therefore, analysis was performed with or without these retracted articles. The reporting bias was assessed by visual inspection into funnel plots [21]. Meta-analysis was conducted by using Review Manager 5.1.

\section{Results}

Included studies

Through electronic searches, snowballing, manual search, contact with the authors, 133 potentially eligible articles were obtained. The detail of flowchart of the studies included in this study was shown in Fig. 1.

A total of 124 studies were subsequently excluded. 65 reports were duplicated from different databases. 53 studies were obviously irrelevant trials of this analysis according to the titles and abstracts. One trial was not randomised controlled trials [22]. One trial lacked non-controlled trial or placebo group [7]. One trial was for the prevention of amphotericin- $B$ induced shivering [23]. We excluded two studies of nefopam for the treatment of intra-operative shivering [24, 25]. Finally, in one trial sample size in each group less than 10 was excluded [26].

Nine eligible randomized clinical trials were eventually included in this analysis, which were published between 1992 and 2013 [13, 27-34] (Table 2). 925 participants from 9 studies were analysed in this study with 474 patients assigned to nefopam group, 131 patients allocated to clonidine group and 320 participants to placebo group. The sample size of enrolled studies ranged from 30 to 371 . Six randomised clinical trials included in this analysis were undergoing general anaesthesia. The patients in two studies were undergoing neuraxial anaesthesia. In only one study, subjects were under conscious sedation. Six trials involved more than one active intervention or studied multiple experimental interventions. Of all trials nefopam was given intravenously. Nefopam was administered at different time points. In three studies nefopam was given before surgery. In 6 trials nefopam was administered at the end of surgery. Among all the enrolled studies, the participants in only one trial underwent active cooling. Three articles were retracted from the published journals due to ethical reason [29, $30,35]$. In five studies, sample size calculation was carried out to control, type one and type two errors.

\section{Risk of bias in included studies}

The quality assessment of the included studies was based on: method of randomization, concealment of allocation, use of blinding, and completeness of data. The detail of the risk of bias was presented in Fig. 2. The funnel plot was presented in Fig. 4 and there was not evident publication bias.

\section{Effects of intervention \\ Risk of perioperative shivering}

9 studies reporting on the episodes of shivering finally entered into the analysis, with 474 patients allocated to nefopam group and 320 patients to placebo group. The control group event rate ranged from $16.7 \%$ to $100 \%$. Overall analysis demonstrated that nefopam was associated with significant reduction in the incidence of shivering (RR,0.08, $95 \%$ CI 0.05-0.13)as shown in Fig. 3. Statistical tests indicated that there was no substantial heterogeneity across the studies $\left(\mathrm{Chi}^{2}=3.71, P=0.88, \mathrm{I}^{2}=\right.$ $0 \%)$, therefore data on the incidence of shivering was combined by using the fixed effect model.

\section{Sensitivity analysis}

1 We applied two sensitivity analyses to the incidence of shivering compared nefopam with placebo.

The fixed effect model favoured prophylactic use of nefopam (RR 0.08, 95 \% CI 0.05-0.13).

The random effect model also favoured the administration of nefopam (RR 0.10, 95 \% CI 0.06-0.15).

2 There were three articles retracted from published journals due to ethnic reasons. This sensitivity analysis considered the retracted studies.

The incidence of shivering was significantly lower in the nefopam group than the placebo group without the retracted articles (RR 0.09, 95 \% CI 0.05- 0.17).

\section{Subgroup analysis}

Subgroup analysis focused on the different methods of anaesthesia, general anaesthesia and neuraxial anaesthesia, as shown in Fig. 5. 

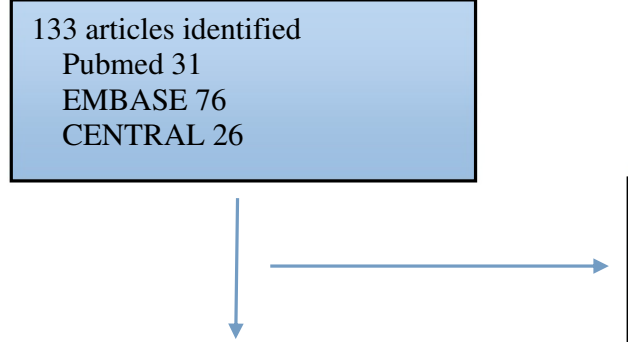

68 potentially trials were screened

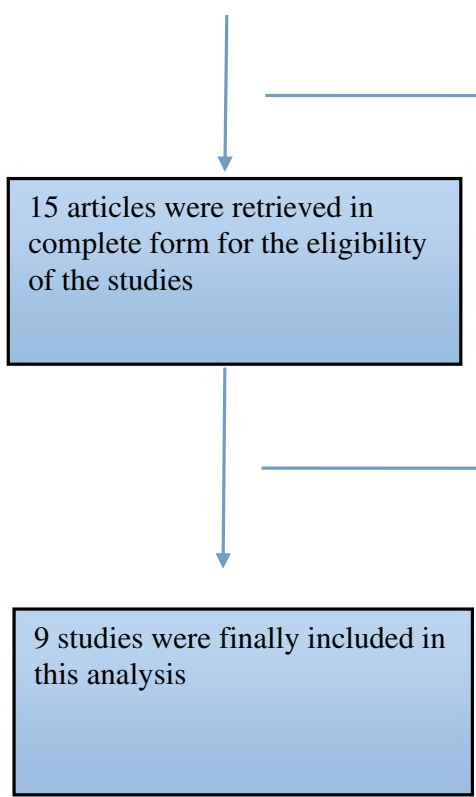

Fig. 1 Flow chart of analyzed studies

General anaesthesia: the RR favoured administration of nefopam (RR 0.10, $95 \%$ CI 0.06, 0.16).

Neuraxial anaesthesia: the RR favoured prophylactic administration of nefopam (RR 0.05, 95 \% CI 0.01, 0.18).

\section{The effect of nefopam on extubation time}

Four studies tested on the effect of nefopam on extubation time compared to the control group. When the data was combined, the extubation time in placebo group was earlier than nefopam group. However, the difference between the two groups did not reach statistical significance (WMD0.92; 95 \% CI $-0.15,1.99$ ), the data was presented in Fig. 6 .

\section{Comparison of nefopam with clonidine}

Clonidine was the most frequently tested substance. Three studies reported on the risk of shivering comparing nefopam with clonidine in total of 407 patients, with 276 allocated to nefopam group and 131 to clonidine group. When the data was combined, the risk of
65 trials were subsequently excluded due to duplicated from different databases
53 articles excluded by scteening the titles and abstracts
1 were not RCT

1 lack control group

1 trial was not in surgical setting

1 limited sample size

2 were nefopam for

treatment of shivering perioperative shivering was significantly lowered in patients received nefopam in comparison with clonidine (RR, 0.34, 95 \% C I0.17-0.70). There was no statistical heterogeneity between nefopam group and clonidine group $\left(\mathrm{Chi}^{2}=0.57, P=0.75, \mathrm{I}^{2}=0 \%\right)$, as shown in Fig. 7 .

\section{Discussion}

We performed a meta-analysis following the guideline of methodology of the Cochrane Handbook for systemic review of interventions. There are two main results in this research. First, this analysis revealed that nefopam was associated with the reduction of rate of shivering not only under general anaesthesia but also neuraxial anaesthesia. As compared with clonidine, nefopam was more efficacious for the prevention of postanaesthetic shivering during the perioperative period. Second, as compared with placebo group, the extubation time in nefopam group did not show statistically significant difference. Besides, none of the enrolled studies reported 
Table 2 Demographic data of included studies

\begin{tabular}{|c|c|c|c|c|c|}
\hline Study & Surgical setting & Type of anesthesia & Comparisons (No. of patients) & Time of administration & Temperature \\
\hline Piper 2004 [29] & Orthopedic or abdominal & General anesthesia & $\begin{array}{l}\text { Nefopam0.2 mg/kg (73); Nefopam0.1 mg/kg (75); } \\
\text { Nefopam0.05 mg/kg (76); Clonidine1.5 Mg/kg (73); } \\
\text { Placebo (74) }\end{array}$ & At the end of surgery & Rectal temperature \\
\hline Bilotta 2001 [33] & Craniotomy & General anesthesia & Nefopam0.12 mg/kg (20); Placebo (20) & At the end of surgery & Bladder temperature \\
\hline Piper 1999 [30] & Abdominal or orthopedic & General anesthesia & 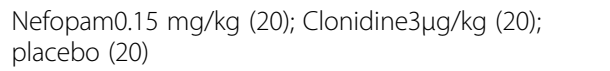 & At the end of surgery & Rectal temperature \\
\hline Bilotta 2002 [13] & Lower limb orthopedic & Neuraxial anesthesia & $\begin{array}{l}\text { Nefopam0.15 mg/kg (30); Tramadol0.5 mg/kg (30); } \\
\text { Placebo (30) }\end{array}$ & Before anesthesia & Urinary-bladder temperature \\
\hline Bilotta 2005 [28] & Interventional neuroradiology & Conscious sedation & $\begin{array}{l}\text { Nefopam0.15 mg/kg (32); Clonidine3 } \mu \mathrm{g} / \mathrm{kg}(38) ; \\
\text { Placebo (31) }\end{array}$ & Before anesthesia & Bladder temperature \\
\hline Rohm 2005 [27] & Abdominal or urological & General anesthesia & $\begin{array}{l}\text { Physostigmine2mg (31); Nefopam10mg (30); } \\
\text { Placebo (28) }\end{array}$ & At the end of surgery & Tympanic temperature \\
\hline Kamal 2011 [34] & Orthopedic & Neuraxial anesthesia & $\begin{array}{l}\text { Nefopam0.2 mg/kg (76); Ketamine + midazolam (75); } \\
\text { placebo (75) }\end{array}$ & Before anesthesia & Tympanic temperature \\
\hline Piper 1998 [31] & Orthopedic or abdominal & General anesthesia & Nefopam0.15 mg/kg (15); Placebo (15) & At the end of surgery & Rectal temperature \\
\hline Tempia 1992 [32] & Radical cystectomy & General anesthesia & Nefopam (27); placebo (27) & At the end of surgery & Not mentioned \\
\hline
\end{tabular}




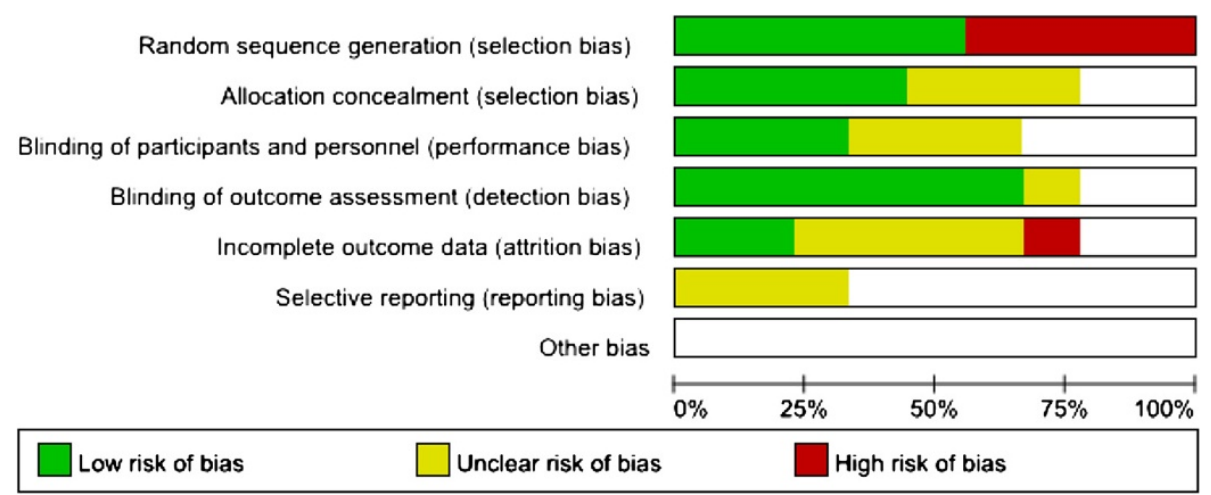

Fig. 2 Risk of bias graph

on any serious side effect of nefopam, such as respiratory depression or cardiovascular effects.

To our knowledge, this is the first meta-analysis of nefopam for preventing perioperative shivering. The methodological quality of most of the included studies was of high quality. There was a large sample size in this analysis, so it was possible to determine the significant difference between the nefopam group and control group. As a comprehensive search has been done by our research group, it is nearly impossible that any important evidence has been ignored.

The aetiology of perioperative shivering is related to hypothermia, decreased sympathetic activity, pyrogen release, postoperative pain, adrenal suppression, depression of vasoconstriction following anaesthesia, blood loss, duration of surgery et al., [36] it has to be kept in mind that maintaining body core temperature have a major effect on the risk of perioperative shivering. Nevertheless, we intentionally kept the patients hypothermic [37] sometimes and it is impossible to keep the body core temperature within normal range all the time. Moreover, shivering occurred even in normothermic patients [38]. Therefore, simple and inexpensive pharmacological strategy is encouraged by anesthesiologists.

A large variety of pharmacological regimens were proposed for the treatment or prevention of shivering. Most of these interventions are efficacious for perioperitive shivering. From the indirect comparison of previous Meta-analysis, nefopam was more efficacious than other interventions [10-12]. This is consistent with our analysis that nefopam was more efficacious than clonidine from the direct comparisons of the included trials. Notwithstanding, there were significantly clinical and statistical heterogeneity among the included studies and report of direct comparison was sparse.

Among all the pharmacological interventions, clonidine was the most frequently reported drug. According to the previous randomized controlled trials and metaanalysis, clonidine was effective in the treatment and prevention of postanesthetic shivering. However, clonidine

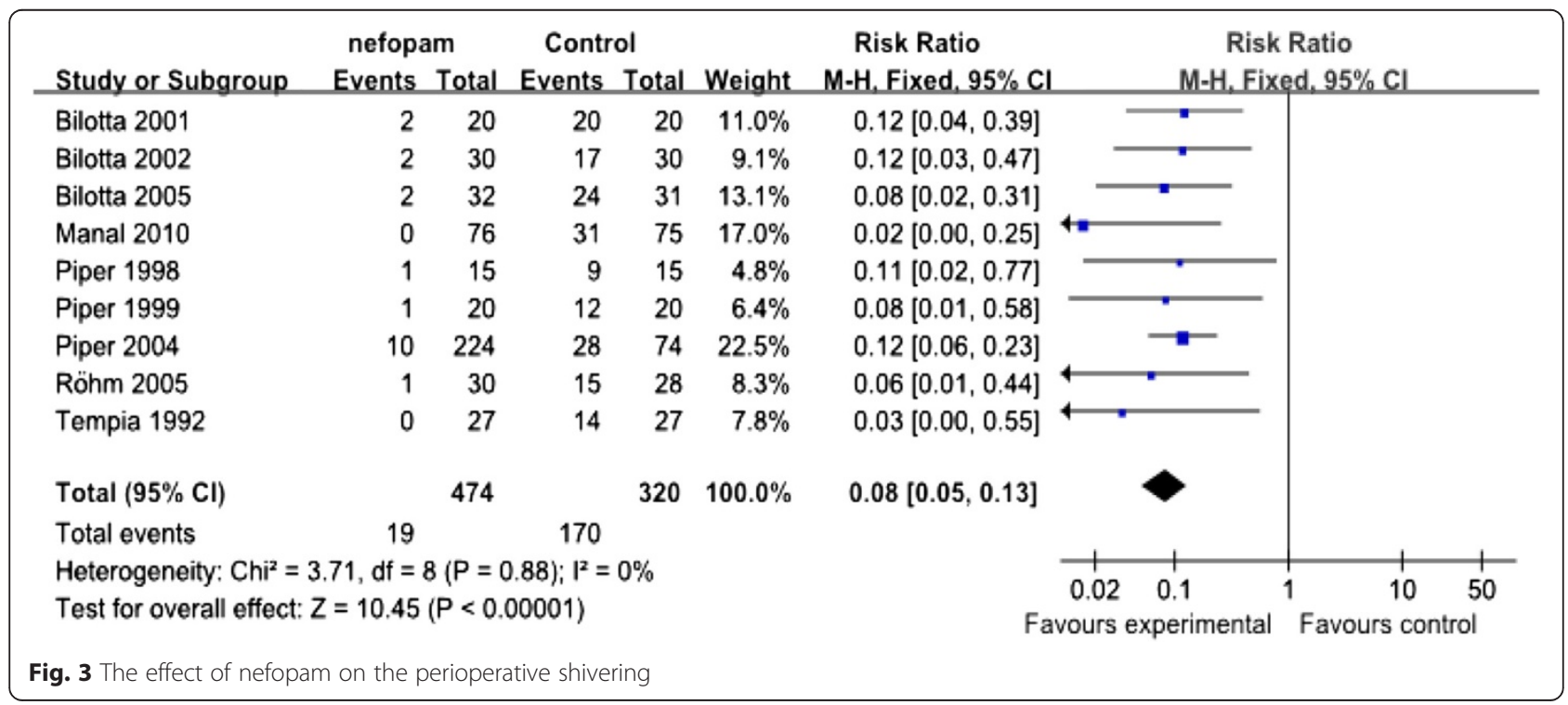




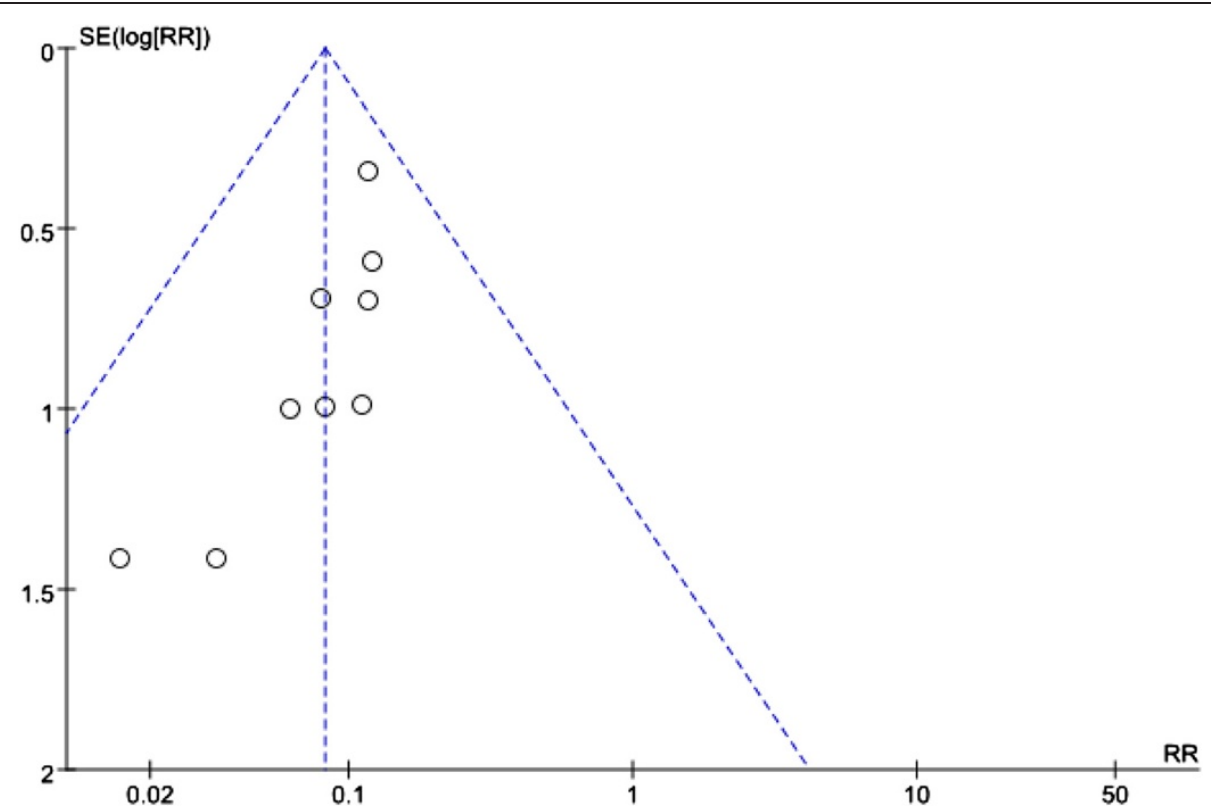

Fig. 4 Funnel plots for the influence of nefopam on the incidence of peri-operative shivering

\begin{tabular}{|c|c|c|c|c|c|c|c|c|}
\hline Study or Subgroup & \multicolumn{2}{|c|}{$\begin{array}{c}\text { nefopam } \\
\text { Events Total }\end{array}$} & \multicolumn{2}{|c|}{ Control } & Weight & $\begin{array}{c}\text { Risk Ratio } \\
\text { M-H, Fixed, } 95 \% \mathrm{Cl}\end{array}$ & \multicolumn{2}{|c|}{$\begin{array}{c}\text { Risk Ratio } \\
\text { M-H, Fixed, } 95 \% \mathrm{Cl}\end{array}$} \\
\hline \multicolumn{7}{|c|}{ 1.2.1 general anaesthesia } & & \\
\hline Bilotta 2001 & 2 & 20 & 20 & 20 & $12.6 \%$ & $0.12[0.04,0.39]$ & & \\
\hline Piper 1998 & 1 & 15 & 9 & 15 & $5.5 \%$ & $0.11[0.02,0.77]$ & & \\
\hline Piper 1999 & 1 & 20 & 12 & 20 & $7.4 \%$ & $0.08[0.01,0.58]$ & & \\
\hline Piper 2004 & 10 & 224 & 28 & 74 & $25.9 \%$ & $0.12[0.06,0.23]$ & & \\
\hline Röhm 2005 & 1 & 30 & 15 & 28 & $9.6 \%$ & $0.06[0.01,0.44]$ & & \\
\hline Tempia 1992 & 0 & 27 & 14 & 27 & $8.9 \%$ & $0.03[0.00,0.55]$ & & \\
\hline Subtotal $(95 \% \mathrm{Cl})$ & & 336 & & 184 & $70.0 \%$ & $0.10[0.06,0.16]$ & & \\
\hline Total events & 15 & & 98 & & & & & \\
\hline \multicolumn{9}{|c|}{ Heterogeneity: $\mathrm{Chi}^{2}=1.27, \mathrm{df}=5(\mathrm{P}=0.94) ; \mathrm{I}^{2}=0 \%$} \\
\hline \multicolumn{9}{|c|}{ Test for overall effect: $Z=8.57(P<0.00001)$} \\
\hline \multicolumn{9}{|c|}{ 1.2.2 neuraxial anaesthesia } \\
\hline Bilotta 2002 & 2 & 30 & 17 & 30 & $10.5 \%$ & $0.12[0.03,0.47]$ & & \\
\hline Manal 2010 & 0 & 76 & 31 & 75 & $19.5 \%$ & $0.02[0.00,0.25]$ & & \\
\hline Subtotal $(95 \% \mathrm{Cl})$ & & 106 & & 105 & $30.0 \%$ & $0.05[0.01,0.18]$ & & \\
\hline Total events & 2 & & 48 & & & & & \\
\hline \multicolumn{9}{|c|}{ Heterogeneity: $\mathrm{Chi}^{2}=2.10, \mathrm{df}=1(\mathrm{P}=0.15) ; \mathrm{l}^{2}=52 \%$} \\
\hline \multicolumn{9}{|c|}{ Test for overall effect: $Z=4.71(P<0.00001)$} \\
\hline Total $(95 \% \mathrm{Cl})$ & & 442 & & 289 & $100.0 \%$ & $0.08[0.05,0.14]$ & & \\
\hline Total events & 17 & & 146 & & & & & \\
\hline \multicolumn{7}{|c|}{ Heterogeneity: $\mathrm{Chi}^{2}=3.68, \mathrm{df}=7(\mathrm{P}=0.82) ; \mathrm{I}^{2}=0 \%$} & $0.01 \quad 0.1$ & $\begin{array}{lll}1 & 10 & 100\end{array}$ \\
\hline \multicolumn{7}{|c|}{ Test for overall effect: $Z=9.80(P<0.00001)$} & \multicolumn{2}{|c|}{ Test for subaroun differences: $\mathrm{Chi}^{2}=0.84 . \mathrm{df}=1(\mathrm{P}=0.36) \cdot \mathrm{I}^{2}=0 \%$} \\
\hline \multicolumn{9}{|c|}{ Fig. 5 The effect of nefopam on perioperative shivering under different anesthesia } \\
\hline
\end{tabular}




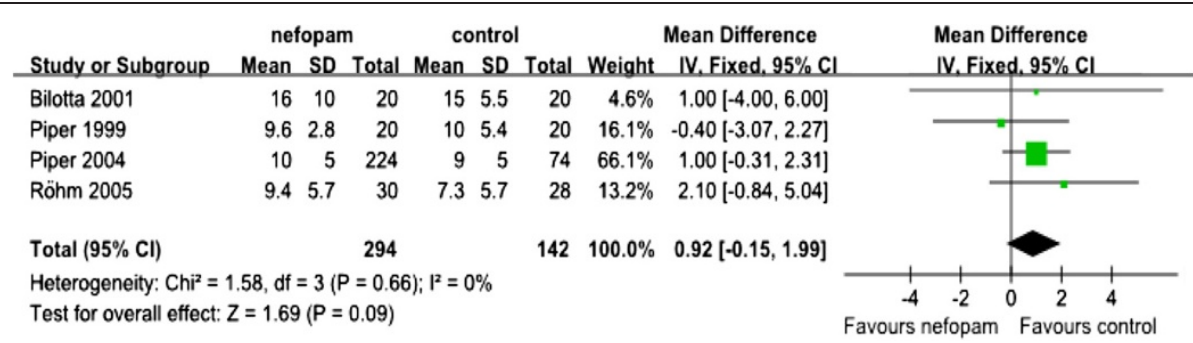

Fig. 6 The infuence of nefopam on the extubation time

was associated with some side effects, for instance, sedative effect, hypotension and bradycardia. Thus, these side effects limited its use. The opioids, such as tramadol, meperidine, alfentanil were also effective in the prevention and treatment of shivering. Nonetheless, these drugs were related to the risk of respiratory depression and postoperative nausea and vomiting (PONV). According to all of the enrolled studies, nefopam was not associated with the increase of the risk of any serious side effect, which contribute much to its safety. None of the included studies reported on any side effect of nefopam. This is inconsistent with the previous reports $[7,39,40]$. This is probably because the subjects of most of the included studies were under general anaesthesia.

It is encouraging that nefopam may possess a specific shivering effect. Alfonsi et al. has shown that nefopam caused a small increase in the core temperature by lowering the shivering threshold and without influencing sweating and vasoconstriction thresholds, therefore minimizing heat loss [41]. Whereas, the other antishivering drugs, such as clonidine [42], meperidine [43], volatiles reduce both shivering and vascular threshold [44], tamadol [45], thus leading to greater heat loss.

There are several limitations in our analysis. Firstly, the methods of reporting the scores of perioperative shivering were different between the trials in this analysis, most of the included studies used Wrench et al. evaluation [46], meanwhile, some trials used their own scoring systems. In this analysis, we only abstracted binary data on absence of shivering to minimise the interpretational risk. Secondly, the sample size of some trials was limited. Small sample size may overestimate the efficacy of nefopam in the prevention of shivering compared with large trial. Thirdly, the baseline of control event rate has a large variability. With extremely frequent control event rate, it may exaggerate the intervention's performance. The patients whom anesthesiologists see in daily clinical work do not have such a high frequent incidence of shivering. This phenomenon challenges the external clinical applicability of this study. Fourthly, reports of the adverse effects were sparse. However, lack of reports does not represent that none occurred. None of the included studies reported on the injection pain, probably because most of the included studies were under general anaesthesia. This was not in agreement with previous study reporting high incidence of injection pain. Finally, in this meta-analysis, reviewers were not blinded to study authors, which might increase the risk of bias. In the future study, investigators should be blinded to study authors, institutions, journal of publication, and results of study.

\section{Conclusions}

In conclusion, we have demonstrated that nefopam inhibit perioperative shivering without producing hypotension and sedative of $\alpha-2$ agonist and respiratory influence of opiates. The better prophylactic antishivering efficacy of nefopam and the side effects of other interventions suggest that among all the interventions, nefopam may hold the best promise. However, side effects of nefopam need to be investigated. Besides, direct comparison of nefopam with other drugs, such as tramadol, meperidine is stillke needed to confirm the relative efficacy.

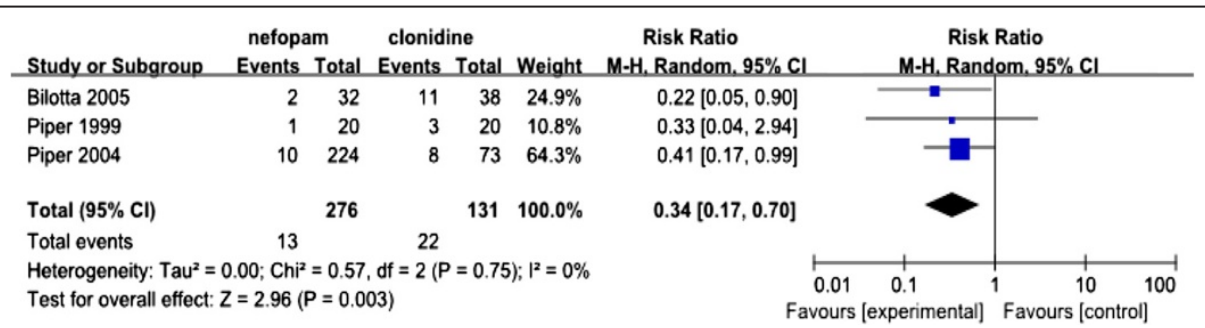

Fig. 7 The influence of nefopam on the peri-operative shivering in comparison with clonidine 
Appendix

Appendix 1 MEDLINE search strategy

\#1 nefopam

\#2 "nefopam" [Mesh]

\#3 \#1 OR \#2

\#4 shivering

\#5"shivering" [Mesh]

\#6 \#4 OR \#5

\#7 \#3 AND \#6

\#8 \#7 Filters Randomized controlled trial

\section{Appendix 2 EMBASE search strategy}

\#1 nefopam

\#2 "nefopam" [EMTREE]

\#3 \#1 OR \#2

\#4 shivering

\#5 “shivering" [EMTREE]

\#6 \#4 OR \#5

\#7 \#3 AND \#6

\#8 \#7 Filters Randomized controlled trial

\section{Appendix 3 Search strategy for CENTRAL, The Cochrane Library}

\#1 MeSH descriptor nefopam explode all trees \#2 nefopam

\#3 \#1 OR \#2

\#4 $\mathrm{MeSH}$ descriptor shivering explode all trees

\#5 shivering

\#6 \#4 OR \#5

\#7 \#3 AND \#6

\section{Abbreviations}

PONV: Postoperative nausea and vomiting; WMD: Weighted mean difference; RR: Relative risk; SD: Standard difference; Cl: Confidence interval.

\section{Competing interests}

The authors declare that they have no competing interests.

\section{Authors' contributions}

ML and YLW conceived the analysis, designed the study. XTW and WDQ participated in the collection of data, statistical analysis. MJL helped to draft the manuscript. All the authors read and approved the final manuscript.

\section{Author details}

${ }^{1}$ Department of anesthesiology, Qianfo shan Hospital, Shandong University, Jinan, Shandong, China. ${ }^{2}$ Department of anesthesiology, The Second affiliated hospital of Shandong Traditional Chinese Medicine University, Jinan, Shandong, China. ${ }^{3}$ Department of nosocomial infection management, the Central Hospital of Taian, Taian, Shandong, China.

Received: 1 March 2015 Accepted: 29 May 2015

Published online: 09 June 2015

\section{References}

1. Li X, Zhou M, Xia Q, Li W, Zhang Y. Effect of parecoxib sodium on postoperative shivering: a randomised, double-blind clinical trial. Eur J Anaesthesiol. 2014:31(4):225-30.

2. Barker SJ, Shah NK. The effects of motion on the performance of pulse oximeters in volunteers (revised publication). Anesthesiology. 1997;86(1):101-8.
3. Horn EP, Sessler DI, Standl T, Schroeder F, Bartz HJ, Beyer JC, et al. Non-thermoregulatory shivering in patients recovering from isoflurane or desflurane anesthesia. Anesthesiology. 1998;89(4):878-86.

4. Jabbary Moghaddam M, Ommi D, Mirkheshti A, Dabbagh A, Memary E, Sadeghi A, et al. Effects of clonidine premedication upon postoperative shivering and recovery time in patients with and without opium addiction after elective leg fracture surgeries. Anesthesiol Pain Med. 2013;2(3):107-10.

5. Mittal G, Gupta K, Katyal S, Kaushal S. Randomised double-blind comparative study of dexmedetomidine and tramadol for post-spinal anaesthesia shivering. Indian J Anaesth. 2014;58(3):257-62.

6. Yousuf B, Samad K, Ullah H, Hoda MQ. Efficacy of tramadol in preventing postoperative shivering using thiopentone or propofol as induction agent: A randomized controlled trial. J Anaesthesiol Clin Pharmacol. 2013;29(4):521-5

7. Kim YA, Kweon TD, Kim M, Lee HI, Lee YJ, Lee KY. Comparison of meperidine and nefopam for prevention of shivering during spinal anesthesia. Korean J Anesthesiol. 2013;64(3):229-33.

8. Mohta M, Kumari N, Tyagi A, Sethi AK, Agarwal D, Singh M. Tramadol for prevention of postanaesthetic shivering: a randomised double-blind comparison with pethidine. Anaesthesia. 2009;64(2):141-6.

9. Tie HT, Su GZ, He K, Liang SR, Yuan HW, Mou JH. Efficacy and safety of ondansetron in preventing postanesthesia shivering: a meta-analysis of randomized controlled trials. BMC Anesthesiol. 2014:14:12.

10. Kranke P, Eberhart LH, Roewer N, Tramer MR. Single-Dose parenteral pharmacological interventions for the prevention of postoperative shivering: A quantitative systematic review of randomized controlled trials. Anesth Analg. 2004;99(3):718-27.

11. Kranke P, Eberhart LH, Roewer N, Tramer MR. Pharmacological treatment of postoperative shivering: a quantitative systematic review of randomized controlled trials. Anesth Analg. 2002;94(2):453-60. table of contents.

12. Park SM, Mangat HS, Berger K, Rosengart AJ. Efficacy spectrum of antishivering medications: meta-analysis of randomized controlled trials. Crit Care Med. 2012;40(11):3070-82.

13. Bilotta F, Pietropaoli P, Sanita R, Liberatori G, Rosa G. Nefopam and tramadol for the prevention of shivering during neuraxial anesthesia. In: Regional anesthesia and pain medicine, vol. 27. 2002. p. 380-4

14. Heel RC, Brogden RN, Pakes GE, Speight TM, Avery GS. Nefopam: a review of its pharmacological properties and therapeutic efficacy. Drugs. 1980;19(4):249-67.

15. Pillans PI, Woods DJ. Adverse reactions associated with nefopam. N Z Med J. 1995;108(1008):382-4.

16. Bhatt AM, Pleuvry BJ, Maddison SE. Respiratory and metabolic effects of oral nefopam in human volunteers. Br J Clin Pharmacol. 1981;11(2):209-11.

17. Rosland $\mathrm{JH}$, Hole K. The effect of nefopam and its enantiomers on the uptake of 5-hydroxytryptamine, noradrenaline and dopamine in crude rat brain synaptosomal preparations. J Pharm Pharmacol. 1990;42(6):437-8

18. Hocker J, Gruenewald M, Meybohm P, Schaper C, Scholz J, Steinfath M, et al. Nefopam but not physostigmine affects the thermoregulatory response in mice via alpha(2)-adrenoceptors. Neuropharmacology. 2010;58(2):495-500.

19. Deeks JJ, Higgins JPT, Altman DG. Analysing data and undertaking metaanalyses. In: Cochrane handbook for systematic reviews of interventions. Chichester: John Wiley \& Sons, Ltd; 2008. p. 243-96.

20. Higgins JPT, Altman DG, Gøtzsche PC, Jüni P, Moher D, Oxman AD, et al. The Cochrane Collaboration's tool for assessing risk of bias in randomised trials, vol. 343. 2011

21. Egger M, Davey Smith G, Schneider M, Minder C. Bias in meta-analysis detected by a simple, graphical test. BMJ (Clin Res Ed). 1997;315(7109):629-34.

22. Schimmenti G, Caruso A, Di Giacinto C, Bellia C, Re MR, Scarpuzza E. Nefopam for the prevention of shivering induced by local-regional anesthesia. Anaesth Intensive Care Italy. 2004;55(4):303-12.

23. Rosa G, Dell'Utri D, Conti G, Pelaia P, Cogliati A, Orsi P, et al. Efficacy of nefopam for the prevention and treatment of amphotericin B-induced shivering. In: Archives of internal medicine, vol. 157. 1997. p. 1589-92.

24. Ferri L, Bertelli G, Innocenti S, Di Grancio R, Tinagli F. The treatment of postoperative shivering with nefopam hydrochloride. Minerva Anestesiol. 1993:59(6):317-20.

25. Izzo $V$, Mariconti $P$, Tiengo M. Action and effectiveness of nefopam chloride in the control of postoperative shivering. Minerva Anestesiol. 1991:57(9):760-2. 
26. Rosa G, Pinto G, Orsi P, De Blasi RA, Conti G, Sanita R, et al. Control of post anaesthetic shivering with nefopam hydrochloride in mildly hypothermic patients after neurosurgery. Acta Anaesthesiol Scand. 1995;39(1):90-5.

27. Rohm KD, Riechmann J, Boldt J, Schuler S, Suttner SW, Piper SN. Physostigmine for the prevention of postanaesthetic shivering following general anaesthesia - a placebo-controlled comparison with nefopam. Anaesthesia. 2005;60(5):433-8.

28. Bilotta F, Ferri F, Giovannini F, Pinto G, Rosa G. Nefopam or clonidine in the pharmacologic prevention of shivering in patients undergoing conscious sedation for interventional neuroradiology. Anaesthesia. 2005;60(2):124-8.

29. Piper SN, Röhm KD, Suttner SW, Maleck WH, Kranke P, Boldt J. A comparison of nefopam and clonidine for the prevention of postanaesthetic shivering: a comparative, double-blind and placebo-controlled dose-ranging study. In: Anaesthesia, vol. 59. 2004. p. 559-64.

30. Piper SN, Suttner SW, Schmidt CC, Maleck WH, Kumle B, Boldt J. Nefopam and clonidine in the prevention of postanaesthetic shivering. Anaesthesia. 1999:54(7):695-9.

31. Piper SN, Schmidt CC, Suttner SW, Kumle B, Triem JG, Maleck WH, et al. Prophylactic nefopam administration for post-anesthetic shivering. In: Anasthesiologie, Intensivmedizin, Notfallmedizin, Schmerztherapie: AINS, vol. 33. 1998. p. 786-9.

32. Tempia A, Livigni S, Castino PM, Fiore G, De Caroli D, Pattono R. The use of nefopam in the prophylaxis and treatment of postoperative shivering. Minerva Anestesiol. 1992;58(9):547-51.

33. Bilotta F, Pietropaoli P, La Rosa I, Spinelli F, Rosa G. Effects of shivering prevention on haemodynamic and metabolic demands in hypothermic postoperative neurosurgical patients. Anaesthesia. 2001;56(6):514-9.

34. Kamal MM, Hussein NS. Prevention of postspinal shivering by using ketamine plus midazolam in comparison with nefopam. Egypt J Chem. 2011;27(1):1-5.

35. Rohm KD, Riechmann J, Boldt J, Schuler S, Suttner SW, Piper SN. Physostigmine for the prevention of postanaesthetic shivering following general anaesthesia - A placebo-controlled comparison with nefopam. Anaesthesia. 2005;60(5):433-8.

36. Sessler DI. Perioperative heat balance. Anesthesiology. 2000;92(2):578-96

37. Bilotta F, Pietropaoli P, La Rosa I, Spinelli F, Rosa G. Effects of shivering prevention on haemodynamic and metabolic demands in hypothermic postoperative neurosurgical patients. Anaesthesia. 2001:56(6):514-9.

38. Kurz A, Sessler DI, Narzt E, Bekar A, Lenhardt R, Huemer G, et al. Postoperative hemodynamic and thermoregulatory consequences of intraoperative core hypothermia. J Clin Anesth. 1995;7(5):359-66.

39. Kim YM, Lim BG, Kim H, Kong MH, Lee MK, Lee IO. Slow injection of nefopam reduces pain intensity associated with intravenous injection: a prospective randomized trial. J Anesth. 2014;28(3):399-406.

40. Evans MS, Lysakowski C, Tramer MR. Nefopam for the prevention of postoperative pain: quantitative systematic review. $\mathrm{Br} J$ Anaesth. 2008;101(5):610-7.

41. Alfonsi P, Adam F, Passard A, Guignard B, Sessler DI, Chauvin M. Nefopam, a Nonsedative Benzoxazocine Analgesic, Selectively Reduces the Shivering Threshold in Unanesthetized Subjects. Anesthesiology. 2004;100(1):37-43.

42. Delaunay L, Bonnet F, Liu N, Beydon L, Catoire P, Sessler DI. Clonidine comparably decreases the thermoregulatory thresholds for vasoconstriction and shivering in humans. Anesthesiology. 1993;79(3):470-4.

43. Kurz A, Ikeda T, Sessler DI, Larson MD, Bjorksten AR, Dechert M, et al. Meperidine decreases the shivering threshold twice as much as the vasoconstriction threshold. Anesthesiology. 1997:86(5):1046-54.

44. Annadata R, Sessler DI, Tayefeh F, Kurz A, Dechert M. Desflurane slightly increases the sweating threshold but produces marked, nonlinear decreases in the vasoconstriction and shivering thresholds. Anesthesiology. 1995;83(6):1205-11.

45. De Witte JL, Kim JS, Sessler DI, Bastanmehr H, Bjorksten AR. Tramadol reduces the sweating, vasoconstriction, and shivering thresholds. Anesth Analg. 1998:87(1):173-9.

46. Wrench IJ, Cavill G, Ward JE, Crossley AW. Comparison between alfentanil, pethidine and placebo in the treatment of post-anaesthetic shivering. $\mathrm{Br} J$ Anaesth. 1997:79(4):541-2.

\section{Submit your next manuscript to BioMed Central and take full advantage of:}

- Convenient online submission

- Thorough peer review

- No space constraints or color figure charges

- Immediate publication on acceptance

- Inclusion in PubMed, CAS, Scopus and Google Scholar

- Research which is freely available for redistribution

Submit your manuscript at www.biomedcentral.com/submit 